\title{
Ventricular tachycardia precipitated by sodium iothalamate (Conray 420) injection during prenylamine treatment: a predictable adverse drug interaction
}

\author{
John S. Duncan* and Lawrence E. Ramsay \\ University Department of Therapeutics, Royal Hallamshire Hospital, Glossop Road, Sheffield, S10 2JF, UK.
}

\begin{abstract}
Summary: A case of ventricular tachycardia occurring after intravenous injection of sodium iothalamate (Conray 420) into a patient taking prenylamine is described. Both of these drugs may cause prolongation of the corrected QT interval and the mechanisms of this potentially fatal drug interaction are discussed.
\end{abstract}

\section{Introduction}

Prenylamine is an antianginal drug which depletes catecholamine stores in adrenergic nerve endings. It frequently prolongs the corrected $\mathrm{QT}$ interval $\left(\mathrm{QT}_{\mathrm{c}}\right.$; Oakley et al., 1980), and this is sometimes extreme. Extreme prolongation of the $\mathrm{QT}_{\mathrm{c}}$ predisposes to serious ventricular arrhythmias and there have been several reports of ventricular tachycardia associated with prenylamine treatment (Bens et al., 1973; Krikler \& Curry, 1976; Puritz et al., 1977; Riccioni et al., 1980; Freestone et al., 1981; Meanock \& Noble, 1981; Grenadier et al., 1982; Tamari et al., 1982). This tachycardia often has the peculiar configuration termed torsade de pointes. To avoid this the manufacturer's data sheet warns that other drugs which also prolong the $\mathrm{QT}_{c}$, for example quinidine or procainamide, should not be prescribed simultaneously and that hypokalaemia must be avoided as this also tends to prolong the $\mathrm{QT}_{\mathrm{c}}$ interval.

Bolus injection of sodium iothalamate can cause substantial prolongation of the $\mathrm{QT}_{\mathrm{c}}$ interval and may constitute a considerable hazard to patients taking prenylamine, and possibly other drugs which also prolong the $\mathrm{QT}_{\mathrm{c}}$ interval. An episode of a life threatening ventricular tachycardia occurring immediately after injection of sodium iothalamate contrast medium in a patient taking prenylamine is reported.

Correspondence: L.E. Ramsay, M.B. Ch.B., F.R.C.P.

* Present address: Department of Neurology, Radcliffe Infirmary, Woodstock Road, Oxford, OX2 6HE, UK.

Accepted: 1 March 1984

\section{Case report}

A 72 year old man was admitted with a $6 \mathrm{~d}$ history of urinary retention and overflow incontinence. Angina had been diagnosed $9 \mathrm{y}$ before and he had taken prenylamine (Synadrin), $60 \mathrm{mg}$ thrice daily, and nifedipine (Adalat), $10 \mathrm{mg}$ thrice daily, for $2 \mathrm{y}$. Before admission, attacks of angina had been mild and infrequent and there was no suggestion of any arrhythmia in his past history. The urinary retention was relieved by an indwelling catheter and an intravenous urogram (IVU) was arranged $4 \mathrm{~d}$ after admission. A few seconds after bolus intravenous injection of $80 \mathrm{ml}$ of sodium iothalamate $70 \% \mathrm{w} / \mathrm{v}$ (Conray 420 ) the patient had a cardiorespiratory arrest. The cardiac rhythm could not be identified because of a faulty oscilloscope but a satisfactory circulatory state was restored immediately by a 100 Joule DC shock.

Ninety minutes later the patient had a further cardiorespiratory arrest. On this occasion the rhythm was identified as a ventricular tachycardia and was converted to sinus rhythm by a 100 Joule DC shock. Prenylamine was stopped and there were no further arrhythmias. Serial electrocardiograms and serum transaminases showed no evidence of a recent myocardial infarction and angina was well controlled by $100 \mathrm{mg} / \mathrm{d}$ of atenolol and $20 \mathrm{mg}$ nifedipine three times per day.

Review of previous electrocardiograms showed that the $\mathrm{QT}_{\mathrm{c}}$ had been $0.41 \mathrm{~s}$ (normal 0.35-0.42 s) in 1974, before prenylamine was started. On the day before the

(C) The Fellowship of Postgraduate Medicine, 1985 
IVU the $\mathrm{QT}_{\mathrm{c}}$ was markedly prolonged to $0.59 \mathrm{~s}$, and at this time the serum potassium was $3.5 \mathrm{mmol} / \mathrm{l}$. After the first cardiorespiratory arrest $(60 \mathrm{~min}$ after the injection of sodium iothalamate) the $\mathrm{QT}_{\mathrm{c}}$ was further prolonged to $0.65 \mathrm{~s}$. After prenylamine was stopped the $\mathrm{QT}_{\mathrm{c}}$ shortened progressively to $0.57 \mathrm{~s}$ at $48 \mathrm{~h}, 0.44 \mathrm{~s}$ at $6 \mathrm{~d}$ and to a normal value of $0.42 \mathrm{~s}$ after $14 \mathrm{~d}$. Before the cardiorespiratory arrest he had not been treated with any other drug known to prolong the $\mathrm{QT}_{c}$, or with diuretics.

\section{Discussion}

Prenylamine frequently causes slight prolongation of the $\mathrm{QT}_{\mathrm{c}}$ interval, for example, to a mean value of $0.44 \mathrm{~s}$ in one study (Oakley et al., 1980). However, prolongation may be extreme in individual patients and this may be associated with dangerous ventricular arrhythmias (Bens et al., 1973; Krikler \& Curry, 1976; Puritz et al., 1977; Riccioni et al., 1980; Freestone et al., 1981; Meanock \& Noble, 1981; Grenadier et al., 1982; Tamari et al., 1982). In this patient the markedly prolonged $\mathrm{QT}_{\mathrm{c}}$ on admission can be attributed to prenylamine because it was not present before the drug was started, it returned to normal after prenylamine was stopped, and the patient was not taking any other drug known to prolong the $\mathrm{QT}_{\mathrm{c}}$. Neither hypokalaemia nor nifedipine can be held responsible as the $\mathrm{QT}_{\mathrm{c}}$ returned to normal despite an increase in the dose of this drug.

The incidence of death associated with IVU examinations has been estimated at 8.6 to 19.0 per million (Berg et al., 1973), but was 7/100,000 in one prospective study of 81,278 examinations (Shehadi, 1975). The causes of these deaths are uncertain and there was no record of electrocardiogram (ECG) monitoring. Various ECG abnormalities have been recorded during intravenous urography, including an increase in heart rate, ST segment depression, atrial and ventricular extrasystoles and $\mathrm{QT}_{\mathrm{c}}$ prolongation (Berg et al., 1973; Small \& Glenn, 1968; Stadalnik et al., 1974; Stadalnik et al., 1977; Pfister \& Hutter, 1980; Lawton et al., 1982).

The observation relevant to the present case was that bolus injection of sodium iothalamate prolonged the $\mathrm{QT}_{\mathrm{c}}$ by a mean of $0.07 \mathrm{~s}$, with the prolongation exceeding $0.1 \mathrm{~s}$ in about one third of patients (Stadalnik et al., 1977). The authors believe that this patient was predisposed to ventricular tachycardia by the added effect of sodium iothalamate on the $\mathrm{QT}_{\mathrm{c}}$, which was already markedly prolonged by prenylamine, and that the arrhythmia was precipitated by a ventricular extrasystole occurring during the prolonged $\mathrm{QT}_{\mathrm{c}}$. The further lengthening of the $\mathrm{QT}_{\mathrm{c}}$ after the injection of sodium iothalamate, from 0.59 to $0.65 \mathrm{~s}$, supports this interpretation.
Alternative explanations for the sequence of events $\frac{\text { की }}{0}$ observed have been considered. It is conceivable that $\precsim$ the first cardiorespiratory arrest, which occurred 3 immediately after injection of sodium iothalamate, $\stackrel{\unrhd}{\unrhd}$ was caused by profound hypotension rather than a $C$ cardiac arrhythmia. However, the prompt response to $\vec{F}$ DC shock and the absence of other features of $\frac{5}{7}$ anaphylaxis argue against this. In any event the second $\frac{}{\circ}$ episode, which was clearly caused by ventricular $\frac{\overline{\bar{N}}}{\mathrm{n}}$ tachycardia, was not preceded by any haemodynamic $\frac{\vec{\sigma}}{\vec{\sigma}}$ disturbance. The possibility that the additional $\cong$ prolongation of the $\mathrm{QT}_{\mathrm{c}}$ interval could have been $\mathrm{a} \%$ consequence of the cardiorespiratory arrests or of $\vec{\circ}$ defibrillation, and not injection of sodium iothalamate, was also considered. Electrocardiographic $\vec{\omega}$ changes do occur after DC shock (Resnekov \& $\frac{\text { D }}{6}$ McDonald, 1967) but $\mathrm{QT}_{\mathrm{c}}$ prolongation does not $\frac{0}{3}$ appear to have been described. These possibilities cannot be dismissed entirely, but the balance of $\stackrel{S}{-}$ evidence strongly favours an interaction between $\searrow$ prenylamine and sodium iothalamate as the cause of $v$ the ventricular tachycardia.

Sodium iothalamate should be added to the list of ${ }^{\mathcal{T}}$ drugs which may be hazardous to patients taking prenylamine. Other contrast media may also prolong $\bar{z}$ the $\mathrm{QT}_{\mathrm{c}}$ and present a similar hazard (Stadalnik et al., 1977). The risk might be reduced by administering the contrast medium by infusion rather than as a bol injection as the former has less effect on the QTO or Injection of contrast medium could, in theor. precipitate dangerous arrhythmias in patients takin other drugs which prolong the $\mathrm{QT}_{\mathrm{c}}$. The authors are aware of only three reports of documented ventricular tachycardia occurring during intravenous urography $\stackrel{\square}{\perp}$ (Stadalnik et al., 1974; Stadalnik et al., 1977). One of $\overrightarrow{\vec{P}}$ these patients was taking procainamide and had a 3 prolonged $\mathrm{QT}_{c}$ of $0.52 \mathrm{~s}$ and another was taking quinidine.

The authors feel that the safety of prenylamine for general use must be questioned. This is the second case 3 of life threatening ventricular arrhythmias associated $\overline{0}$ with prenylamine presenting to this unit within $5 \mathrm{y}$. (Freestone et al., 1981). Prenylamine is not widely used $\delta$ and no more than two or three patients taking it are $₹$ seen by this unit in any year. Considering this, and the $\frac{\text { 의 }}{7}$ other cases which have been reported it is suspected $\supset$ that the incidence of this serious adverse reaction may be unacceptably high. It is also of concern that this $\bar{N}$ problem, which is well known to cardiologists, may not be recognized by the general physician who may $\tilde{O}$ attribute the development of arrhythmias and sudden $\underset{\omega}{N}$ death in patients with angina to the disease, and not to 0 the treatment. The risks of prenylamine need to be 0 quantified precisely in long term prospective studies. $\frac{}{\Phi}$ Until this is done the drug should be used only as a last $\stackrel{?}{+}$ resort in patients who cannot be managed with other 0 antianginal drugs such as beta blockers, long acting $\frac{\mathrm{O}}{\Phi}$ 
nitrates and calcium antagonists.

When prenylamine must be used it is mandatory to monitor the $\mathrm{QT}_{\mathrm{c}}$ with serial ECGs, to avoid hypokalaemia and to avoid any other drug which may also prolong the $\mathrm{QT}_{\mathrm{c}}$. These precautions are stated clearly

\section{References}

BENS, J.L., DUBOISSET, M., QUIRET, J.C., LESBRE, J.P. \& BERNASCONI, P. (1973). Syncopes par torsade de pointes induites ou favourisees par la prenylamine. Archives des Maladies du Coeur et des Vaisseaux, 66, 1427.

BERG, G.R., HUTTER, A.M. \& PFISTER, R.C. (1973). Electrocardiographic abnormalities associated with intravenous urography. New England Journal of Medicine, 289, 87.

FREESTONE, S., JACKSON, P.R. \& RAMSAY, L.E. (1981). Life threatening ventricular arrhythmia. The Practitioner, 225, 541.

GRENADIER, E., ALPAN, G., KEIDAR, S. \& PALANT, A (1982). Atrio-ventricular block after administration of lignocaine in patients treated with prenylamine. Postgraduate Medical Journal, 58, 175.

KRIKLER, D.M. \& CURRY, P.V.L. (1976). Torsade de pointes, an atypical ventricular tachycardia. British Heart Journal, 38, 117.

LAWTON, G., PHILLIPS, T. \& DAVIES, R. (1982). Alterations in heart rate and rhythm at urography with sodium diatrizoate. Acta Radiologica, 23, 107.

MEANOCK, C.I. \& NOBLE, M.I.M. (1981). A case of prenylamine toxicity showing the torsade de pointes phenomenon in sinus rhythm? Postgraduate Medical Journal, 57, 381 .

OAKLEY, D., JENNINGS, K., PURITZ, R., KRIKLER, D.M. \& CHAMBERLAIN, D.A. (1980). The effect of prenylamine on the QT interval of the resting electrocardiogram in patients with angina pectoris. Postgraduate Medical Journal, 56, 753.

PFISTER, R.C. \& HUTTER, A.M. (1980). Cardiac alterations during intravenous urography. Investigative Radiology, 15, S239. in the manufacturer's data sheet but are not always heeded by prescribing doctors. Sodium iothalamate and other contrast media should be added to the list of drugs to be avoided in patients taking prenylamine.

PURITZ, R., HENDERSON, M.A., BAKER, S.N. \& CHAMBERLAIN, D.A. (1977). Ventricular arrhythmias caused by prenylamine. British Medical Journal, 2, 608.

RESNEKOV, L. \& McDONALD, L. (1967). Complications in 220 patients with cardiac dysrhythmias treated by phased direct current shock, and indications for electroconversion. British Heart Journal, 29, 926.

RICCIONI, N., BARTOLOMEI, C. \& SOLDANI, S. (1980). Prenylamine induced ventricular arrhythmias and syncopal attacks with Q-T prolongation. Report of a case and comment on therapeutic use of lignocaine. Cardiology, 66, 199.

SHEHADI, W.H. (1975). Adverse reactions to intravascularly administered contrast media. A comprehensive study based on a prospective survey. American Journal of Roentgenology, 124, 145.

SMALL, M.P. \& GLENN, J.F. (1968). Comparative evaluation of intravenous pyelographic contrast media and assessment of associated electrocardiographic alterations. Journal of Urology, 99, 223.

STADALNIK, R.C., DAVIES, R., VERA, Z., HILLIARD, G. \& DA SILVA, O. (1974). Ventricular tachycardia during intravenous urography. Report of two cases. Journal of the American Medical Association, 229, 686.

STADALNIK, R.C., VERA, Z., DA SILVA, O., DAVIES, R., KRAUS, J.F. \& MASON, D.T. (1977). Electrocardiographic response to intravenous urography: prospective evaluation of 275 patients. American Journal of Roentgenology, 129, 825 .

TAMARI, I., RABINOWITZ, B. \& NEUFELD, H.N. (1982). Torsade de pointes due to prenylamine controlled by lignocaine. European Heart Journal, 3, 389. 